\title{
Why do People Participate in Collaborative Consumption? Evidence from Bicycle Sharing Data
}

\author{
Haoxiao Li*, Yuntao Zhang \\ School of Economics and Management, Xidian University, Xi'an 710126, China \\ *Corresponding author e-mail: hxli_xd@163.com
}

\begin{abstract}
Collaborative consumption is an emerging consumption model to achieve rational allocation of resources by sharing the right to use idle resources based on Internet or mobile Internet. This study proposes a more comprehensive definition of collaborative consumption and five distinctive characteristics of collaborative consumption about economy, technology, ecology, society and institution. Based on the characteristics, this study presents a model of the influencing factors to explain consumers ' intention to participate in collaborative consumption. It develops and tests a structural equation model using partial least squares path modelling and survey data collected from a bicycle sharing users. The result indicates consumers' intention to participate in collaborative consumption is motivated by economic benefits, convenience, sustainability, sense of belonging and trust. The most important factor is convenience, the least influencing factor is sense of belonging. Furthermore, in order to promote sustainability of collaborative consumption, this study gives advice to enterprises in practice.
\end{abstract}

KEYWORDS: collaborative consumption, characteristics, influencing factors, structural equation model, bicycle sharing

\section{Introduction}

Attitudes towards consumption have shifted in recent years and brought increasing concern over ecological, societal, and developmental impact. Considering this, the concept of "sharing" is getting more and more popular. Until now, bicycle sharing, umbrella sharing, car sharing, charger sharing and other sharing things appear around us frequently. So this is an economic era which we call "sharing economy". According to the report of the Data Research Center, the scale of China's sharing economy industry reached 539.48 billion yuan in 2017, with a growth rate of $41.6 \%$ [1]. And collaborative consumption is the concept of sharing economy that focus on the specific aspects of consumption. 
However, since the development of collaborative consumption is still in its infancy, it has inevitably encountered some problems. Evidence suggests that consumers are resistant to participate in some collaborative consumption patterns. For example, some products like sharing cars may not suitable for sharing among consumers because the deposit is too high to bear. The resistance of consumers led to bankrupt of some collaborative consumption enterprises and venture capital firms, and more seriously, it will lead to a waste of social resources and unsustainable development of collaborative consumption.

Why do consumers resist? This study argues that collaborative consumption may not grasp the real needs and necessary needs of consumers, and product strategy has caused consumer dissatisfaction. In order to grasp consumers needs to survive, enterprises should know what factors are affecting people using products or services. Only by understanding these factors can enterprises create better goods and services, venture capital firms can better evaluate each collaborative consumer enterprise and invest in it, and collaborative consumption industry will develop healthily in the future.

The key aims of this paper are to explain consumer engagement in the collaborative consumption context and to draw practical implications from the empirical results. The research question for the study is: what factors explain a consumer's intentions to participate in the online collaborative consumption context? In order to answer this question, this paper deeply studies the characteristics of collaborative consumption and conducts empirical research with data. The conclusions make a contribution to collaborative consumption in theory and in practice.

\section{Literature review}

\subsection{Definition of Collaborative Consumption}

Different papers give different definitions of collaborative consumption. For example, Botsman and Rogers define it as traditional sharing, bartering, lending, trading, leasing, gifting and exchange activities that are redefined by technology and peer communities [2]; Mou et al. believe that collaborative consumption refers to an emerging culture and new economic form that enjoys goods, knowledge, time or services in the form of sharing, exchange, bartering, group buying, trading and leasing based on the Internet and mobile Internet platforms [3].

In order to describe the collaborative consumption completely, this study define collaborative consumption as: collaborative consumption is a kind of consumption pattern that consumers access, give, and share the right to use goods or services by sharing, exchanging, bartering, trading, and leasing based on the Internet and mobile Internet platform to obtain monetary income or other compensation. The fundamental difference between collaborative consumption and traditional consumption patterns is that collaborative consumption emphasizes the right to use products or services rather than owning them. 


\subsection{Characteristics of Collaborative Consumption}

This paper summarizes the following for distinctive characteristics of collaborative consumption based on existing studies: (1) Economy: collaborative consumption based on the right to use can let participants gain benefits or save costs [4]. In the 21st century, idle items and overcapacity bring costs, while collaborative consumption emphasizes the right to use so that two or more individuals involved in collaborative consumption can share costs, thereby reducing consumption, and saving costs. (2) Technology: Collaborative consumption emerges as a high-tech phenomenon [5]. Russell Belk pointed out that collaborative consumption was born in the Internet era [4]. (3) Ecology: collaborative consumption is a kind of economic form that promotes sustainable development and is also a kind of consumer culture that save resources [6]. (4) Society: The community can be established by sharing activities [7]. The essence of the sharing economy is the sharing of resources. Sharing means the interaction between individuals. The interaction that connects the scattered individuals forms the community. Belk argues that sharing activities tends to make people feel like they are part of like-minded group [8]. (5) Institution: Compared with the rapid development of collaborative consumption, the related policy system is far away from perfection [9].

\section{Research model and hypotheses}

Based on the definition and characteristics of collaborative consumption, this study argues five key factors that affect consumers' participation in collaborative consumption: namely economic benefits; Convenience; Sustainability; Sustainability; Sense of belonging; Trust.

Economic benefits are defined as the extent to which users perceive that participating in collaborative consumption can obtain money or save cost. Tang et al. found that personal gains positively affected the perceived usefulness of users in collaborative consumption [10]. Freiberg et al. found clear evidence that the car sharing industry was creating consumer surplus and substituting rental for ownership [11]. Bardhi and Eckhardt conducted a qualitative study of the access economy for cars and found consumers largely motivated by self-interest and utilitarianism [12]. Such Economic benefits is likely to have a positive impact on the intention to participate in collaborative consumption. Thus, it is hypothesized that:

H1: Economic benefits have a positive effect on the intention to participate in collaborative consumption.

Convenience refers to the extent of time, effort, and psychological cost savings perceived by a user. Moeller et al. found that users' preference for non-ownership consumption patterns was significantly affected by "convenience-oriented" [13]. Collaborative consumption emerges as a high-tech phenomenon, and the Internet and mobile Internet save users time and effort in searching for things. Because the using process is relatively complicated, it brings time and psychological costs to the 
ISSN 2616-5783 Vol. 1, Issue 1: 84-93, DOI: 10.25236/AJHSS.040012

user. In this process, if these costs of the user can be reduced by convenience, it is beneficial to increase the user's intention to participate. Thus, it is hypothesized that:

H2: Convenience has a positive effect on the intention to participate in collaborative consumption.

Sustainability is defined as the extent to which users perceive that participating in collaborative consumption can save resources and reduce consumption. Tussyadiah found that sustainability is one of the drivers of user engagement in collaborative consumption through exploratory study [14]; Amasawa et al. presented design approach to induce behavioral shifts to product sharing through a case study on laundry activities in Japan, and found that it can reduce $1.8 \%$ of greenhouse gas emissions and $16 \%$ of resource use [15]. If users perceive that participating in collaborative consumption is an environmentally friendly behavior, they are more willing to participate in it. So there is hypothesis as follow:

H3: Sustainability has a positive effect on the intention to participate in collaborative consumption.

Sense of belonging is defined as the extent to which the user considers himself to belong to a certain group or a certain community. Like other social networks, members of collaborative consumption networks are likely to feel a sense of belonging to the community they engage with. The community can be established by sharing activities [7]. The essence of the sharing economy is the sharing of resources. Sharing means the interaction between individuals. This interaction makes users feel a part of like-minded people, thereby meeting their inner needs and enhancing their intention to participate. So there is hypothesis as follow:

H4: Sense of belonging has a positive effect on the intention to participate in collaborative consumption.

Trust is a psychological expectation or subjective desire that one of the participants believes that other participants will perform their obligations in accordance with its own expectations [15]. Cox et al. emphasized trust and reciprocity to be a core variable explaining why individuals tend to cooperate with each other [16]. Because collaborative consumption is an emerging form of consumption and lack complete institutional norms, Trust will reduce the anxiety and worry in the process of participation for users, reduce their hesitation and doubt in deciding whether to participate or not. Such trust may has a positive impact on the intention to participate in collaborative consumption. Thus, it is hypothesized that:

H5: Trust has a positive effect on the intention to participate in collaborative consumption.

Based on the above hypotheses, the research model proposed in this paper is shown in Figure 1. 


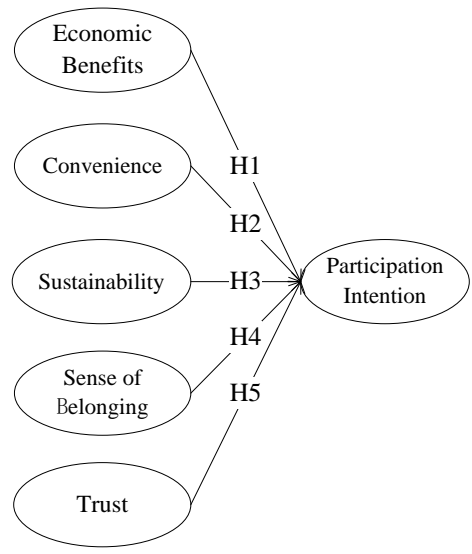

Figure. 1 Research Model

\section{Methodology}

Table 1 Measurement items and sources.

\begin{tabular}{|c|c|c|}
\hline Variable & Item & Source \\
\hline \multirow{3}{*}{ Economic Benefits } & By using Bicycle Sharing I am saving money. & \multirow{3}{*}{ [17] } \\
\hline & Bicycle Sharing is a low-cost option. & \\
\hline & Using Bicycle Sharing has reduced my spending on daily travel. & \\
\hline \multirow{3}{*}{ Convenience } & I can search for sharing bicycle anytime, anywhere. & \multirow{3}{*}{ [18] } \\
\hline & I can get a sharing bicycle anytime, anywhere. & \\
\hline & $\begin{array}{l}\text { The use of Bicycle Sharing is not complicated, which makes me } \\
\text { feel very convenient. }\end{array}$ & \\
\hline \multirow{3}{*}{ Sustainability } & $\begin{array}{l}\text { I feel as if I am making a contribution to the environment by using } \\
\text { Bicycle Sharing. }\end{array}$ & \multirow{3}{*}{ [19] } \\
\hline & \begin{tabular}{|l|} 
Using Bicycle Sharing is environmentally-friendly. \\
\end{tabular} & \\
\hline & Using Bicycle Sharing helps save natural resources. & \\
\hline \multirow{3}{*}{ Sense of belonging } & $\begin{array}{l}\text { Using Bicycle Sharing allows me to be part of a group of like- } \\
\text { minded people. }\end{array}$ & \multirow{3}{*}[20]{} \\
\hline & $\begin{array}{l}\text { Using Bicycle Sharing allows me to belong to a group of people } \\
\text { with similar interests. }\end{array}$ & \\
\hline & $\begin{array}{l}\text { Using Bicycle Sharing makes me feel like I am part of a group of } \\
\text { like-minded people. }\end{array}$ & \\
\hline \multirow{3}{*}{ Trust } & I trust that Bicycle Sharing will be displayed as expected. & \multirow{3}{*}[20]{} \\
\hline & $\begin{array}{l}\text { Bicycle Sharing provides a robust and safe environment in which } \\
\text { I can use the service. }\end{array}$ & \\
\hline & $\begin{array}{l}\text { I trust that the Bicycle Sharing provider provides enough } \\
\text { safeguards to protect me from liability for damage I am not } \\
\text { responsible for. }\end{array}$ & \\
\hline \multirow{2}{*}{$\begin{array}{l}\text { Participation } \\
\text { Intention }\end{array}$} & $\begin{array}{c}\text { All things considered, I expect to continue using Bicycle Sharing } \\
\text { often in the future. }\end{array}$ & \multirow[t]{2}{*}[21]{} \\
\hline & It is likely that I will frequently use Bicycle Sharing in the future. & \\
\hline
\end{tabular}

\section{Published by Francis Academic Press, UK}


This study adapts measurement items from existing self-determination theory scale, collaborative consumption scale, and supplements them to capture Bicycle Sharing users behavior. The English version of the scale items are shown in table 1. Items for constructs within the research model were measured using 5-point Likert scales ranging from $1=$ strongly disagree to $5=$ strongly agree, where $3=$ =neutral.

Data were collected using online and offline survey from users of using Bicycle Sharing between October and December in 2017. We collected 412 questionnaires in total, in all, 373 useful responses were received. The characteristics of the final sample are shown in table 2.

Table 2 Sample characteristics.

\begin{tabular}{|c|c|c|c|c|c|c|c|}
\hline Variable & Options & Frequency & Proportion & Variable & Options & Frequency & Proportion \\
\hline \multirow{2}{*}{ Gender } & Males & 189 & $50.7 \%$ & \multirow{6}{*}{ Education } & $\begin{array}{c}\text { High school or } \\
\text { below }\end{array}$ & 25 & $6.7 \%$ \\
\hline & Females & 184 & $49.3 \%$ & & Undergraduate & 281 & $82.0 \%$ \\
\hline \multirow{4}{*}{ Age } & Under 18 & 12 & $3.2 \%$ & & Master & 51 & $13.7 \%$ \\
\hline & $18-25$ & 319 & $85.5 \%$ & & Ph.D. & 12 & $3.2 \%$ \\
\hline & $25-30$ & 24 & $6.4 \%$ & & Other & 4 & $1.1 \%$ \\
\hline & Over 30 & 18 & $4.8 \%$ & & & & \\
\hline \multirow{6}{*}{ Tenure } & Not used & 49 & $13.1 \%$ & \multirow{6}{*}{ Brand } & OFO & 268 & $71.8 \%$ \\
\hline & $\begin{array}{c}\text { Less than } \\
\text { a month }\end{array}$ & 51 & $13.7 \%$ & & Mobike & 224 & $60.1 \%$ \\
\hline & $\begin{array}{c}1 \text { to } 3 \\
\text { months }\end{array}$ & 52 & $13.9 \%$ & & Bluegogo & 23 & $6.2 \%$ \\
\hline & $\begin{array}{l}4 \text { to } 6 \\
\text { months }\end{array}$ & 76 & $20.4 \%$ & & XiaoMing & 7 & $1.9 \%$ \\
\hline & $\begin{array}{l}7 \text { to } 12 \\
\text { months }\end{array}$ & 82 & $22.0 \%$ & & Youon & 11 & $2.9 \%$ \\
\hline & $>1$ year & 63 & $16.9 \%$ & & Other & 38 & $10.2 \%$ \\
\hline
\end{tabular}

\section{Result}

The main statistical tool used in this study was SmartPLS 3.2 (SmartPLS GmbH, Bönningstedt, Germany). Table 3 and 4 examined the reliability, discriminant validity and convergent validity of the constructs. Table 3 shows that all the standard loadings of measurement items were above 0.7 and significant at the 0.001 level, and metrics for the final scales revealed that the Cronbach's Alpha scores and composite reliability (CR) values were greater than 0.7 . The results support scale reliability. 
Academic Journal of Humanities \& Social Sciences

ISSN 2616-5783 Vol. 1, Issue 1: 84-93, DOI: 10.25236/AJHSS.040012

Table 3 Reliability and Composite Reliability (CR).

\begin{tabular}{|c|c|c|c|c|}
\hline Variable & Items & Loadings & Cronbach's $\alpha$ & CR \\
\hline \multirow{3}{*}{ Economic Benefits } & PE1 & 0.832 & \multirow{3}{*}{0.721} & \multirow{3}{*}{0.843} \\
\hline & PE2 & 0.737 & & \\
\hline & PE3 & 0.832 & & \\
\hline \multirow{3}{*}{ Convenience } & PC1 & 0.814 & \multirow{3}{*}{0.765} & \multirow{3}{*}{0.863} \\
\hline & PC2 & 0.828 & & \\
\hline & PC3 & 0.828 & & \\
\hline \multirow{3}{*}{ Sustainability } & SU1 & 0.859 & \multirow{3}{*}{0.859} & \multirow{3}{*}{0.914} \\
\hline & SU2 & 0.889 & & \\
\hline & SU3 & 0.900 & & \\
\hline \multirow{3}{*}{ Sense of Belonging } & BL1 & 0.794 & \multirow{3}{*}{0.841} & \multirow{3}{*}{0.903} \\
\hline & BL2 & 0.915 & & \\
\hline & BL3 & 0.897 & & \\
\hline \multirow{3}{*}{ Trust } & TR1 & 0.700 & \multirow{3}{*}{0.705} & \multirow{3}{*}{0.831} \\
\hline & TR2 & 0.844 & & \\
\hline & TR3 & 0.847 & & \\
\hline \multirow{2}{*}{ Participation Intention } & IN1 & 0.896 & \multirow{2}{*}{0.787} & \multirow{2}{*}{0.903} \\
\hline & IN2 & 0.919 & & \\
\hline
\end{tabular}

Table 4 shows the square root of average variance extracted (AVE) were greater than 0.71, and AVE were all greater than the correlation coefficient, which indicates the data support convergent validity.

Table 4 Correlation matrix and AVE square root

\begin{tabular}{ccccccc}
\hline & BL & EB & IN & PC & SU & TR \\
\hline BL & 0.870 & & & & & \\
EB & 0.370 & 0.802 & & & & \\
IN & 0.248 & 0.549 & 0.908 & & & \\
PC & 0.244 & 0.485 & 0.628 & 0.823 & & \\
SU & 0.358 & 0.565 & 0.525 & 0.583 & 0.833 & \\
TR & 0.475 & 0.466 & 0.532 & 0.596 & 0.561 & 0.790 \\
\hline
\end{tabular}

Note: EB----Economic Benefits; BL----Sense of Belonging; SU----Sustainability; IN----Participation Intention; PC----Convenience; TR----Trust.

Figure 4 reports standardized regression coefficients in the research model. All of them were positive and significant at the 0.001 level, supporting all the research hypotheses. 
ISSN 2616-5783 Vol. 1, Issue 1: 84-93, DOI: 10.25236/AJHSS.040012

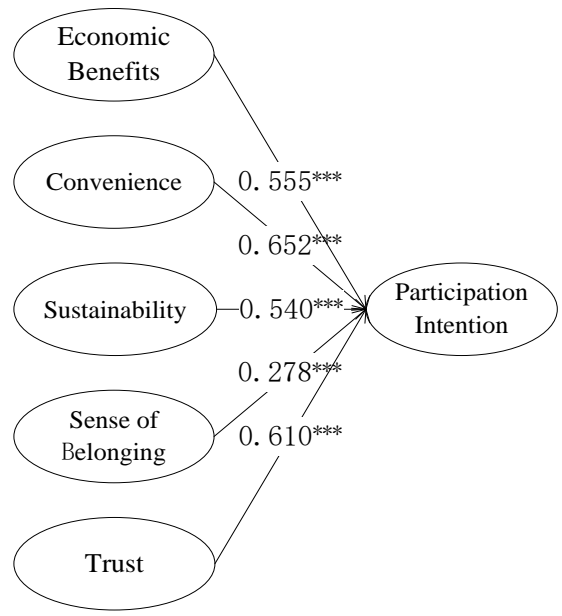

Figure. 2 Standardized model estimates. Note: All regression weights were significant at the 0.001 level (two-tailed test).

\section{Discussion and conclusions}

Collaborative consumption is seen as a way to promote sustainable social development, and multiple models of it have proven to save resources and protect the environment [22]. However, inevitably some problems have arisen in its development. This study believes that these problems arise because the consumer motivations to participate in collaborative consumption are unclear. In order to make the enterprises successful and let the collaborative consumption achieve sustainable development, this paper studies the influencing factors of consumer participation based on characteristics of collaborative consumption, the model in this study makes a significant contribution to the emergent stream of literature on the sharing economy.

Through empirical results, the most influential factor is convenience. It indicates consumers pay more attention to the efficiency gains brought by convenience in this fast- paced society. And the next important factor is trust. This shows that the imperfections of the current system have brought insecurity to consumers, making them discouraged. The order of influence of the remaining three factors is economic benefits, sustainability, and sense of belonging. This indicates that the premise of consumers participating in collaborative consumption is that participating in collaborative consumption can bring them economic, environmental and social benefits. From the nature of these five variables, convenience and economic benefits are more about perceived benefits, while trust, sustainability and sense of belonging are more about psychological needs.

This research also has implications for practice of collaborative consumption enterprises.

Published by Francis Academic Press, UK 
First, from convenience, enterprises should optimize the process of product use to reduce the using effort from the perspective of consumers. Second, for the trust, enterprises should establish a good self-image through social media, and security measures should be taken to protect consumer privacy. Third, from economic benefits, collaborative consumption enterprises should adopt multiple forms of operational strategies to help consumers earn profits or reduce costs, rather than just considering a single low price strategy. Fourth, from sustainability, the enterprises' products or services should be closely linked to the theme of green and environmental protection, which is the essence of collaborative consumption. Finally, from sense of belonging, enterprises should establish online and offline communities to accumulate social capital for consumers.

This study has limitations that point to the directions of future research. First, this study considers the influencing factors from the characteristics of collaborative consumption, and future research can also consider from a broader perspective. Second, this study focus on just one type of collaborative consumption, and testing the model in other online sharing contexts is recommended.

\section{References}

[1] Bosidata. Research Report on China's Sharing Economic Market Prospects and Investment Opportunities in 2018-2023. Bosi Data Research Center, 2017.11.

[2] Botsman R, Rogers R. What's Mine is Yours: The Rise of Collaborative Consumption. Harper Business: New York, NY, 2010.

[3] Mou H.S., Xiao X., Ning L.J. Research on Business Model Innovation of Collaborative Consumption. Academic search for Truth and Reality, 2013 (1): 51-56.

[4] Belk R. You are what you can access: Sharing and collaborative consumption online. Journal of Business Research, 2014, 67 (8): 1595-1600.

[5] John N. Sharing, Collaborative Consumption and Web 2.0. MEDIA@LSE Electronic Working Papers, 2013.

[6] Leismann K., Schmitt M, Rohn H., and Baedeker C. Collaborative Consumption: Towards a Resource-Saving Consumption Culture. Resources, 2013: 184-203.

[7] Albinsson P., Perera B. Alternative marketplaces in the 21st century: Building community through sharing events. Journal of Consumer Behaviour, 2012, 11 (4): 303-315.

[8] Belk R. Why Not Share Rather Than Own. Annals of the American Academy of Political \& Social Science, 2007, 611 (1): 126-140.

[9] Barnes S.J., Mattsson J. Understanding current and future issues in collaborative consumption: A four-stage Delphi study. Technological Forecasting \& Social Change, 2016, 104: 200-211.

[10] Tang Y.Q., Fan C.R., Tan D.Q. Research on Influencing Factors of Chinese Consumers' Participation in Collaborative Consumption in the Sharing Economy. Soft Science, 2017, 31 (10): 136-139.

[11] Fraiberger S., Sundararajan A. Peer-to-Peer Rental Markets in the Sharing Economy. Social Science Electronic Publishing, 2015.

\section{Published by Francis Academic Press, UK}


ISSN 2616-5783 Vol. 1, Issue 1: 84-93, DOI: 10.25236/AJHSS.040012

[12] Bardhi F., Eckhardt G.M., 2012. Access-based consumption: the case of carsharing. Journal of Consumer Research. 2012, 39, 881-898.

[13] Moeller S., Wittkowski K. The burdens of ownership: reasons for preferring renting. Journal of Service Theory and Practice, 2010, 20 (2): 176-191 [58].

[14] Tussyadiah Iis P. An Exploratory Study on Drivers and Deterrents of Collaborative Consumption in Travel [J]. Information \& Communication Technologies in Tourism, 2015.

[15] Pavlou P.A., Gefen D. Building Effective Online Marketplaces with InstitutionBased Trust. Information Systems Research, 2004, 15 (1): 37-59.

[16] Cox J.C., Ostrom E., Walker M., Castillo AJ, Coleman E, Holahan R, Schoon M, Steed B. 2009. Trust in private and common property experiments. Southern Economic Journal 75 (4): 957-975.

[17] Barnes S.J., Mattsson J. Understanding collaborative consumption: Test of a theoretical model. Technological Forecasting \& Social Change, 2017, 118: 281292.

[18] Li P.C., Zhong Y.S. Consumers'Adoption of Mobile O2O Commerce Based on DTPB. Journal of Industrial Engineering/Engineering Management, 2016, 30 (4): 102-111.

[19] Hamari J., Sjöklint M., Ukkonen A. The Sharing Economy: Why People Participate in Collaborative Consumption. Journal of the Association for Information Science and Technology, 2015, 67 (9): 2047-2059.

[20] Möhlmann M. Collaborative consumption: determinants of satisfaction and the likelihood of using a sharing economy option again. Journal of Consumer Behaviour, 2015, 14 (3): 193-207.

[21] Liu F., Zhao X.F., Zhang J.L. and Tang Q. Study on Consumer Usage Intention of Mobile Coupons: From the Perspective of Personal Characteristics and Motivations. Management Review, 2016, 28 (2): 93-102.

[22] Jung J., Koo Y. Analyzing the Effects of Car Sharing Services on the Reduction of Greenhouse Gas (GHG) Emissions. Sustainability, 2018, 10, 539. 